\section{The organization of health services and visceral leishmaniasis: an integrated intervention to improve diagnosis and treatment}

\author{
Contribuição à organização de serviços de saúde com \\ atenção à leishmaniose visceral: um trabalho \\ integrado para o diagnóstico e tratamento \\ da doença
}

\author{
1 Centro de Pesquisas René \\ Rachou, Fundação Oswaldo \\ Cruz, Belo Horizonte, Brasil. \\ 2 Instituto de Ciências \\ Biológicas, Universidade \\ Federal de Minas Gerais, Belo \\ Horizonte, Brasil. \\ Correspondence \\ Z. M. P. Luz \\ Laboratório de Pesquisa \\ Clínica, Centro de Referência \\ em Leishmaniose, Centro \\ de Pesquisas René Rachou, \\ Fundação Oswaldo Cruz. \\ Av. Augusto de Lima 1715, \\ Belo Horizonte, $M G$ \\ 30190-002, Brasil. \\ profeta@cpqrr.fiocruz.br
}

\begin{abstract}
The objective of this study, carried out in municipalities located in a metropolitan region of Brazil, was to promote the early diagnosis and prompt treatment of visceral leishmaniasis. In the intervention model a health professional underwent training that covered all procedures involved in assisting patients with suspected visceral leishmaniasis. The professionals then returned to their municipalities where they implemented a workplan with the following aims: (a) at least one physician able to diagnose and treat patients; (b) training of professionals for the laboratorial diagnosis of visceral leishmaniasis; (c) delivery of information on visceral leishmaniasis to the health workers. The implementation process was evaluated by follow-up meetings. Attendance of health professionals at the meetings, implementation of the workplan, and the visceral leishmaniasis case fatality rate before (1998-1999) and after (20012002) implementation of the model were used in the analysis. Among the 36 municipalities in the region, 22 were enrolled. Eight (36.3\%) guaranteed at least $50 \%$ attendance in the meetings, and 14 (63.6\%) had less than 50\% attendance with no activities implemented. The fatality rate decreased in the municipalities that implemented the activities.
\end{abstract}

Visceral Leishmaniasis; Health Services; Lethality
Zélia M. P. Luz 1

Mariângela Carneiro ${ }^{2}$

Virgínia Schall 1

Ana Rabello 1

\section{Introduction}

Visceral leishmaniasis is particularly prevalent in Bangladesh, India, Nepal, Sudan and Brazil, with these five countries together accounting for $90 \%$ of the global visceral leishmaniasis burden ${ }^{1}$. The disease is closely associated with poverty and usually affects the poorest people in the poorest countries. It is estimated that in India, $88 \%$ of leishmaniasis patients have a daily income of less than US $\$ 2.00$ a day ${ }^{2}$. Control of this disease is not easy on account of: (1) the diversity of its epidemiological profile, since it occurs in different ecological regions; (2) the limitation of diagnostic methods, which are invasive, expensive, and require a complex infrastructure that demands different and complex approaches in different settings; (3) the drawback of the therapeutic intervention, as long parenteral courses of pentavalent antimonial agents remain the treatment of choice in the vast majority of endemic countries, with an unacceptable frequency and intensity of adverse effects.

In Brazil, leishmaniasis is a notifiable disease, and the Brazilian control program that started more than 40 years ago is based on the free delivery of specific drug therapy and on vector and domestic reservoir control 3. Vector control, essentially for the Lutzomyia longipalpis species, is performed by the spraying of insecticides, and reservoir control is performed by serological testing of domestic dogs (the main reservoir in urban 
areas). These measures are expensive and rely on limited tools for the reservoir diagnosis, which results in much operational impairment, including long delays following sampling, diagnosis and culling 4,5 . The sustainability of these measures is difficult, and in the last 22 years, the number of cases of the disease has increased. A 20 -fold increase in the number of cases was observed, with 160 cases notified in 1980, rising to 3,220 in 2005 . The disease is found in four of the five regions of Brazil and from 1990 to 2005, the average national incidence rate was $1.8 / 100,000$ inhabitants varying from between 1.0 to $2.9 / 100,000$ inhabitants (Secretaria de Vigilância em Saúde, Ministry of Health).

The incidence rate from 2001-2005 varied widely at state and city levels. For example, in the state of Tocantins in the north of the country, the incidence increased from 0.8 in 1990 to 13.5/100,000 inhabitants in 2005. High incidence rates were also observed in other states such as Mato Grosso do Sul in the Mid-west region, different states in the Northeast and in Minas Gerais in the Southeastern region. Although the disease has historically been found in rural areas, its epidemiological pattern has changed, and the urbanization of visceral leishmaniasis has been observed in metropolitan areas in major Brazilian cities, where the number of cases has increased sharply 6,7,8. This phenomenon is closely related to migration to urban areas, particularly in poor areas where facilities for housing and sanitation are inadequate 9,10. Another cause of concern is the high fatality rate of visceral leishmaniasis in Brazil. Although the response to treatment is satisfactory with no significant resistance to antimonials, during the last decade, deaths caused by visceral leishmaniasis have ranged from $3 \%$ in 1995 to $7 \%$ in 2005 , on average 3,11 . The reasons for this high fatality rate are still unknown but could possibly be attributed to the lack of prompt diagnosis and treatment 8 .

In an attempt to improve the clinical and laboratory diagnosis of leishmaniasis in the municipalities of a metropolitan region in Brazil, an intervention model focusing on the organization of health services was developed. Follow-up activities performed in these municipalities and the possible impact of the model on the fatality rate for visceral leishmaniasis are presented below.

\section{Methods}

\section{Study area}

This work was carried out in the Metropolitan Region of Belo Horizonte located in Minas Gerais State in the Southeastern region of Brazil. At the beginning of this work the Metropolitan Region of Belo Horizonte had a population of 4,606,318, with $95 \%$ being urbanized (Instituto Brasileiro de Geografia e Estatística. Demographic Census, 2000; http://www.ibge.gov.br) and was composed of 36 municipalities of which more than $50 \%$ have already reported autochthonous cases of visceral leishmaniasis. With the exception of the capital Belo Horizonte, which was not included in this study due to its complexity, all of the 35 municipalities of the Metropolitan Region of Belo Horizonte were invited to participate. In the preparatory phase, information from the 36 municipalities with regard to the structure of health services was gathered by means of a questionnaire that was completed by the health manager from each municipality. This provided information on the number of reported cases of visceral leishmaniasis, its fatality rate, the infrastructure of health services, and their interest in participating ${ }^{8}$. In short, the first autochthonous case of visceral leishmaniasis in the Metropolitan Region of Belo Horizonte was reported in 1989, and the number of notified cases rose from 30 cases in 1994 to 251 in 2005. During the previous five years, the fatality rate had ranged from $7 \%$ to $15 \%$, with a remarkable geographic expansion of the disease. Only $9.7 \%$ of the 36 municipalities reported that infra-structure for at least one laboratorial method for diagnosing leishmaniasis was available. Therefore, almost $80 \%$ of patients had to be referred to state capital, Belo Horizonte, located 17 to $30 \mathrm{~km}$ away 8 .

\section{Conceptual framework}

\section{- Study design}

This is an intervention study without random sampling. The first stage of the research involved meetings with the epidemiology sector representative of the Metropolitan Health Administration at the Minas Gerais State Ministry of Health to discuss the model and proposal. The program was set up according to the following steps: (1) determining through questionnaires the number of reported cases of leishmaniasis, its fatality rate, the infrastructure of health services and interest in participating at the municipality level; (2) definition of a workplan with a list of activities, person responsible and timetable; (3) training of lab 
technicians on laboratorial diagnosis and physicians on clinical assessments and adequate treatment; (4) implementation of the local diagnosis and medical assistance; (5) follow-up of the implementation process through regular meetings. All the municipalities of the Metropolitan Region of Belo Horizonte were invited to participate, independently of the reported number of visceral leishmaniasis cases. This decision was based on the profile of the disease in the region, with an increase in the number of cases, the high case fatality rate and its rapid geographical spread.

\section{- The intervention model}

The model was designed to create a network that included researchers and health professionals from the municipalities of the Metropolitan Region of Belo Horizonte in order to provide adequate care for patients with leishmaniasis. The aim of this network was to increase the response capacity of health services related to visceral leishmaniasis mainly in diagnosis and treatment. In each municipality, a health worker was selected by the local health manager to act as the leishmaniasis reference and to be the local leader for implementing activities. The selection of the professional was unrelated to his or her functions in the service. In this way, all interested municipalities could participate even if only a reduced staff was available.

To act as the reference, the professional had to carry out the following tasks: (a) to undertake a training that covered all procedures involved in assistance to patients with suspected visceral leishmaniasis; (b) to discuss and help the local health service team in implementing activities and (c) to participate in the follow-up to the activities. The workplan involved achieving the following: (i) guaranteeing the presence of at least one physician able to diagnose and treat patients; (ii) training local staff in routine laboratorial diagnoses and (iii) delivering information on visceral leishmaniasis to health workers, especially physicians. The reference professional was expected to act as the person responsible for identifying the main needs of the health services related to the clinical and laboratory diagnosis of the disease. The local staff and health units selected to become the leishmaniasis point of care were defined by both the local health manager and the reference professional. All of the support necessary to train the health workers was provided by the Leishmaniasis Reference Center at the René Rachou Center/Oswaldo Cruz Foundation (LRC/FIOCRUZ).

Implementation of activities was coordinated by researchers at LRC/FIOCRUZ, along with the epidemiology sector representative at the Metropolitan Health Administration of the Minas Gerais State Ministry of Health. Follow-up occurred through periodic meetings.

\section{- Leishmaniasis training}

Training activities began on May 2000 and were divided into theoretical and practical classes. The aim of the training was to provide the health professional with a general overview of the disease and prepare them to discuss the implementation of activities with the health manager and local team. The training was delivered by a group of leishmaniasis experts and consisted of a series of lectures and ambulatory and laboratory sessions covering distribution, causative agents, transmission, life cycle, symptoms, treatment, prevention and control. Emphasis was mainly put on clinical and laboratory diagnosis and on the therapeutic features of leishmaniasis. In addition, one module was specifically devoted to the discussion of the importance of notification and the need for reliable data relating to the disease. The course was held at the LRC/FIOCRUZ, making use of the ambulatory and laboratory facilities. Most of the classes were similar for all health workers irrespective of their profession and/or function. The theoretical and practical courses lasted 16 and 24 hours respectively. In the ambulatory training for physicians, activities included clinical evaluation of patients and case discussions. Laboratory activities consisted of parasitological and serological diagnoses. Additional trainings were performed according to the needs identified by the local team.

\section{- Follow-up meetings}

As mentioned above, the program started in May 2000. After the completion of all training courses, follow-up was carried out by means of 21 regular meetings, held between September 2000 and September 2003. Two weeks beforehand, letters were sent to the professionals' health service and home address, inviting them to participate in the program. Messages by electronic mail were sent to those who had this facility.

Attendance at the follow-up meetings was considered an indicator of the maintenance of the link between the professionals and the program's coordinators. On these occasions, the reference professional from each municipality described the situation regarding the proposed activities. In this manner, all participants would know how the activities were conducted and the implementation of the proposed agenda in each municipality. Therefore, the meetings served to 
promote communication among those involved who could contribute with suggestions for improvements. The meetings were useful in updating discussions particularly in the areas of control, diagnosis, and treatment, and were held with leishmaniasis specialists who helped to facilitate discussions about relevant problems and solutions, as well as how to optimize the setup of the health service and implementation of activities.

\section{- Data analysis}

Outcomes were analyzed taking into account the attendance at the follow-up meetings, activities implemented, and the visceral leishmaniasis fatality rate. In relation to attendance, municipalities were grouped into those which that participated in $50 \%$ or more of the meetings and those that participated in less than $50 \%$ of follow-up meetings.

Analysis of the completion of planned activities was based on the workplan. The indicator was calculated taking into account the implemented activity compared with what was planned, as defined in the workplan. In this manner, $100 \%$ corresponded to all implemented activities, $67 \%$ to two in three and $33 \%$ to one in three.

The possible effect of the program on the visceral leishmaniasis fatality rate was evaluated comparing the municipalities with a an attendance rate at follow-up meetings of $50 \%$ or more, before (1998-1999) and after (2001-2002), and those with attendance of less than $50 \%$. Both were compared with another municipality, Belo Horizonte which as mentioned previously, was not included in the program. Data including number of cases and number of deaths due to the disease were gathered through the Metropolitan Health Administration of the Minas Gerais State Ministry of Health.

\section{Results}

Twenty-two municipalities and 21 professionals (one professional represented two municipalities) were enrolled in the project. The professional group was composed of eight physicians, four pharmacists, three nurses, one veterinary doctor, and five technicians. Of these, $13(62 \%)$ had permanent and eight (38\%) had temporary employment contracts. The main reasons listed by the 14 municipalities that did not participate were a lack of infrastructure and human resources or the absence of cases of the disease.

Initially, monitoring of the work was made by local visits by the coordinators (researchers at the LRC/FIOCRUZ and the head of the epidemiol- ogy sector at the Metropolitan Health Administration) as well as through periodical meetings with all reference professionals. Nevertheless, as of 2001 the monitoring of implemented activities was undertaken mainly at the follow-up meetings, largely because of a change in personnel at the head of epidemiology at the Ministry, who had an important role in local visits.

The follow-up of proposed activities, after the training course, was carried out by means of 21 meetings, held between September 2000 and September 2003. In 2000, the average attendance was $67 \%$. Nevertheless, over the next three years (2001-2003) it dropped to $36 \%, 32 \%$, and $24 \%$, respectively. Of the 22 municipalities, eight (36.3\%) had an attendance higher than $50 \%$ and the other $14(63.7 \%)$ had an attendance of less than $50 \%$. The implementation of activities was evaluated in all of the 22 municipalities and it was observed in the group of eight municipalities that a physician was trained in four municipalities and the local staff training had been implemented in three municipalities. Strategies to deliver visceral leishmaniasis information to health workers, mainly physicians, have been established in seven municipalities. Among the other 14 municipalities, only one performed the distribution of information. In the group composed of the eight municipalities that participated in $50 \%$ or more meetings, the proportion of activities implemented varied from 0 to $100 \%$ (Table 1). In five municipalities, $67 \%$ or more of the activities were implemented, in two this rate was $33 \%$, and in one no activities were implemented. The visceral leishmaniasis fatality rate in two of these five municipalities was $33 \%$ and $50 \%$ before the implantation of activities, and even though the number of visceral leishmaniasis cases increased, the fatality rate decreased to zero after the implementation of activities. All implemented activities were accomplished in two municipalities. Although one municipality had attendance at the meetings of $59 \%$ or more, it did not implement any activities. In this municipality, the fatality rate was $13 \%$ in the years 1998 1999 before the implementation of activities and reached $20 \%$ during the period from 2000-2002.

Training of local staff was related to visceral leishmaniasis serology, but only four of these municipalities had adequate infrastructure to carry this out. One of them was the municipality that did not implement any activities.

The average number of cases of visceral leishmanisis in the group composed of the 14 municipalities was variable and low during the years between 2000 and 2002 (Table 2). In contrast, in the group composed of the eight municipalities, these numbers were significantly higher (Table 2). 
Description and percentage of activities implemented by the eight municipalities with $50 \%$ or more attendance at follow-up meetings.

\begin{tabular}{lcccc}
\hline Municipalities & Physician training & $\begin{array}{c}\text { Activities } \\
\text { Local staff training }\end{array}$ & Implementation (\%) \\
& Information delivery & \\
1 & Yes & Yes & Yes & 100 \\
2 & Yes & Yes & Yes & 100 \\
3 & Yes & No & Yes & 67 \\
4 & Yes & No & Yes & 67 \\
5 & No & Yes & Yes & 67 \\
7 & No & No & Yes & 33 \\
8 & No & No & Yes & 33 \\
\hline
\end{tabular}

Table 2

Average number of visceral leishmaniasis cases during the three years of activities in 22 municipalities.

\begin{tabular}{|c|c|c|c|c|}
\hline \multirow{2}{*}{$\begin{array}{l}\text { Attendance at } \\
\text { follow-up meetings }\end{array}$} & \multirow[t]{2}{*}{ Municipalities (n) } & \multicolumn{3}{|c|}{ Average number of visceral leishmaniasis cases } \\
\hline & & 2000 & 2001 & 2002 \\
\hline $50 \%$ or more & 8 & $6 \pm 6.92$ & $4.75 \pm 5.92$ & $8.37 \pm 10.79$ \\
\hline Less than $50 \%$ & 14 & $0.5 \pm 0.94$ & $1.14 \pm 2.14$ & $1.28 \pm 1.77$ \\
\hline$p$ value * & - & 0.04 & 0.0002 & 0.04 \\
\hline
\end{tabular}

* $\mathrm{p}$ value: $\mathrm{F}$ statistic

Despite the relatively short time span of the study, the possible effect of the implemented activities on the visceral leishmaniasis fatality rate was evaluated for the years 2001-2002 and compared with the period 1998-1999 (Table 3). This analysis was based on the number of cases of visceral leishmaniasis and its average fatality rate and included 7 of the 8 municipalities which implemented the activities fully or partially. For this analysis, Belo Horizonte (capital of the state) and the 14 municipalities which did not participate in the meetings were included (Table 3 ).

In all of the municipalities, the number of cases rose between 1998 and 2002. In the group which implemented the activities, the fatality rate was $22.2 \%$ before implementation. However, after the implementation of activities, this rate significantly decreased to $3.4 \%$. The relative change in this group showed an $84.5 \%$ reduction in the fatality rate after implementation of activities. In contrast, in Belo Horizonte, the fatality rate increased $10.7 \%$ in the years 2001-2002 in comparison with 1998-1999. In Belo Horizonte, the fatality rate was $12.2 \%$ before the activities and $13.5 \%$ after. In the group with the 14 municipalities, an increase in the fatality rate after the activities was observed (Table 3 ).

\section{Discussion}

The program strategy aimed to achieve a close cooperation between researchers, health workers and professionals in an attempt to optimize the use of their knowledge and experience on visceral leishmaniasis. During the program, all processes were monitored and evaluated. The importance of evaluation is to provide scientific and social information regarding a particular intervention and to reach a conclusion which can be translated into action 12. Adherence to the program was based on the regularity of attendance by professionals at follow-up meetings and, although it was not the sole criterion, the frequency was used to indicate the link that professionals had with the program. In general, the 
Number of cases of visceral leishmaniasis and fatality rate in municipalities with $50 \%$ or more attendance at follow-up meetings that had implemented some activity, in comparison with Belo Horizonte and municipalities with less than $50 \%$ attendance, before and after implementation of activities.

\begin{tabular}{|c|c|c|c|c|c|}
\hline \multirow[t]{2}{*}{ Municipalities ( $n$ ) } & \multicolumn{2}{|c|}{ Before (1998-1999) } & \multicolumn{2}{|c|}{ After (2001-2002) } & \multirow[t]{2}{*}{ Relative change (\%) } \\
\hline & Number of cases & Fatality rate (\%) & Number of cases & Fatality rate (\%) & \\
\hline $50 \%$ or more attendance (7) & 18 & 22.2 & 88 & 3.4 & $84.5 * \downarrow$ \\
\hline Less than $50 \%$ attendance (14) & 8 & 0.0 & 34 & 14.7 & $14.7 \uparrow$ \\
\hline Belo Horizonte (1) & 57 & 12.2 & 133 & 13.5 & $10.7 \star \star \uparrow$ \\
\hline
\end{tabular}

Note: Belo Horizonte was not included in the program.

${ }^{*} p=0.01$ (chi-square test);

$\star \star p=0.84$ (chi-square test).

adherence of municipalities was low, and some aspects may have had an influence. One of the motivations of participating could be related to the presence of cases of the disease in each municipality. In the municipalities that participated in less than $50 \%$ of the implementation meetings, the average number of cases of visceral leishmaniasis was significantly lower than that observed in the group of municipalities with $50 \%$ or more attendance of the follow-up. Seven of 14 of these municipalities had no cases during the first years of the activities implementation. In contrast, the average number of cases in the group of the eight municipalities in the first years was 12 times higher than that in the other group. In the next two years (2001-2002) these values were 4.0 and 6.5. Moreover, some of the reference professionals faced difficulties in taking a lead in implementation of activities and in establishing adequate interlocution with the services, thereby contributing to the low participation of these 14 municipalities. Another factor which affected participation was the type of professional employment contract. In the eight municipalities with $50 \%$ or more attendance of the meetings, all professionals had permanent contracts in the health service, whereas in the other group the majority of professionals had temporary employment contracts. The nature of the employment contract represents a cause for concern, because in the Brazilian health system, there is a high professional turnover in groups with temporary contracts. In general, the temporary contracts are precarious and vulnerable. There was a higher turnover in the group with 14 municipalities than in the group with eight. Another problem interfering with the participation of the municipalities was the high replacement rate of the head of the epidemiology sector at the Metropolitan Health Administration, who had an important role in the management and intermediation between the reference professional and the local health office, providing more sustainability to the proposals in the municipality. Analyses of the processes of inter-sectional actions on a program aimed at reducing infant mortality in the State of Bahia, Brazil reported difficulties in implementation due to the high turnover of professionals responsible for program implementation. Another problem identified was the lack of stable staff in the coordination of the same program 13 .

Among the eight municipalities, seven implemented, either partially or totally, the activities and one did not implement any activities at all. The main reason for this was related to internal administrative problems and changes in the local health office.

To place a special emphasis on disease information, the coordinator and reference professionals decided to produce a visceral leishmaniasis pamphlet and a booklet in order to target the population and health professionals. The pamphlet produced in 2001 during implementation of activities was evaluated among health professionals and lay persons, and its potential for disseminating visceral leishmaniasis information was evident 14 . Among the seven municipalities which implemented the activities there was an intensive dissemination of visceral leishmaniasis information, especially among physicians. This intensive dissemination of information on visceral leishmaniasis among these seven municipalities was probably one of the main reasons for the reduction in the fatality rate.

Despite the relatively short time span of the intervention, changes in the service and the possible effect on the visceral leishmaniasis fatality rate were estimated. In general, evaluation of the program impact requires a considerable invest- 
ment of time to observe, analyze and measure the changes in the health indicators being studied 15 .

The average number of visceral leishmaniasis deaths after the implementation of activities was lower than the baseline estimates in the group with municipalities that partially or completely implemented the activities. Comparisons were made based on the numbers of visceral leishmaniasis cases before (1998-1999) and after implementation of the first set of activities in 2001 and 2002. Two years were not considered in this analysis: the year 2000 because the training started in this year, and the year 2003 due to the fact that the data related to the number of cases and deaths was incomplete. The comparison between the group with the seven municipalities and Belo Horizonte helped in the understanding of whether the implemented activities contributed to reduce the fatality rate. Belo Horizonte did not participate in the project, and of the municipalities in the Metropolitan Region of Belo Horizonte, only the city of Belo Horizonte itself had a profile of number of cases that was similar to the group with eight municipalities. In contrast, the fatality rate in Belo Horizonte did not decrease significantly, and the situation got worse during the period of evaluation. It is important to note that with the exception of the regular control measures recommended by the Brazilian Ministry of Health no other interventions had been implemented in any of these municipalities during the period of the project.

In recent years, the impact of the leishmaniasis control program in Brazil has been the object of many discussions, due to the increase in the number of visceral leishmaniasis cases observed since 19804 . The Brazilian campaign involves mass treatment of patients, elimination of reservoir hosts (dogs) and widespread spraying of insecticides. Nevertheless, these two latter measures are very complex and difficult to implement, particularly the elimination of dogs.

Considering our results, the reduction of visceral leishmaniasis deaths may be a sentinel health event to measure the quality of health services, as used to address infant and maternal mortality 16 . The work is ongoing, and one of the challenges is to guarantee its sustainability. Modifications such as creating and strengthening reference professional teams, involving basic care professionals and professionals who deal with control measures, were introduced and may facilitate the sustainability of activities.

This process evaluation provided stimulating results that can contribute to the health sector in which Brazil is decentralized. Decentralization is an important principle of the Unified $\mathrm{Na}$ tional Health System (SUS) with transference of responsibilities and resources to municipalities. This kind of complex system requires, among other things, skilled human resources able to empower the local service. Although many operational difficulties occurred and despite the limitations of the study, the results and information obtained were stimulating and pointed to the potential of this model for contributing to the reduction of avoidable deaths related to visceral leishmaniasis.

\section{Resumo}

Estudo com o objetivo de diagnosticar precocemente e tratar de forma adequada a leishmaniose visceral fo $i$ desenvolvido em municípios de uma região metropolitana no Brasil. O modelo de intervenção previa a capacitação de um profissional de saúde que, após participar de um treinamento sobre diferentes aspectos da leishmaniose visceral, estaria apto a articular no seu município a implantação de um plano de ação que contemplaria três atividades: (a) ter pelo menos um médico para o diagnóstico e tratamento dos casos, (b) treinar profissionais para o diagnóstico laboratorial, (c) divulgar a informação sobre a leishmaniose visceral para profissionais de saúde. A implantação das atividades foi acompanhada por meio de reuniões durante três anos. Para as análises foram utilizados como indicadores: a presença dos profissionais às reuniões, a implantação das atividades e a redução da letalidade, antes (1998-1999) e após (2001-2002) a implantação. Entre os 36 municípios da região, 22 participaram. Oito (36,3\%) tiveram $50 \%$ ou mais de presença às reuniões e 14 (63,6\%) tiveram menos que 50\% e nenhuma atividade implantada. Houve decréscimo da letalidade entre os municípios que implementaram as atividades.

Leishmaniose Visceral; Serviços de Saúde; Letalidade 


\section{Contributors}

Z. M. P. Luz participated in the conception and design of the intervention and conducted all the descriptive stages of the methodology, including analysis of results and drafting of the article. A. Rabello participated in the conception and design, analysis and revision of the paper. M. Carneiro and V. Schall participated in the analysis and interpretation of data, and revision of the paper.

\section{Acknowledgments}

The authors would like to thank the health professionals who participated in the project. We would also like to thank Marion Kussel for the English revision and comments, and the Fundação Oswaldo Cruz (FIOCRUZ) and the Brazilian Council for Scientific and Technological Development (CNPq) for their financial support.

\section{References}

1. World Health Organization. Control of the leishmaniasis. Geneva: World Health Organization; 1990. (Technical Report Series, 793).

2. Special Programme for Research and Training in Tropical Diseases. Strategic direction for leishmaniasis research. http://www.who.int/tdr/diseases/ leish/direction.htm (accessed on 22/Nov/2006).

3. Ministério da Saúde. Manual de vigilância e controle da leishmaniose visceral. Brasíla: Ministério da Saúde; 2006.

4. Costa CH, Vieira JB. Changes in the control program of visceral leishmaniasis in Brazil. Rev Soc Bras Med Trop 2001; 34:223-8.

5. Palatnik-de-Sousa CB, Santos WR, França-Silva JC, Costa RT, Reis AB, Palatnik M, et al. Impact of canine control on the epidemiology of canine and human visceral leishmaniasis in Brazil. Am J Trop Med Hyg 2001; 65:510-7.

6. Costa CHN, Pereira HF, Araújo MV. Epidemia de leishmaniose visceral no Estado do Piauí, Brasil, 1980-1986. Rev Saúde Pública 1990; 24:361-72.

7. Jeronimo SM, Oliveira RM, Mackay S, Costa RM, Sweet J, Nascimento ET, et al. An urban outbreak of visceral leishmaniasis in Natal, Brazil. Trans R Soc Trop Med Hyg 1994; 88:386-8.

8. Luz ZMP, Pimenta DN, Cabral AL, Fiúza VO, Rabello A. A urbanização das leishmanioses e a baixa resolutividade diagnóstica em municípios da Região Metropolitana de Belo Horizonte. Rev Soc Bras Med Trop 2001; 34:249-54.

9. Desjeux P. The increase in risk factors for leishmaniasis worldwide. Trans R Soc Trop Med Hyg 2001; 95:239-43.

10. Costa CH, Werneck GL, Rodrigues Jr. L, Santos MV, Araújo IB, Moura LS, et al. Household structure and urban services: neglected targets in the control of visceral leishmaniasis. Ann Trop Med Parasitol 2005; 99:229-36.
11. Werneck GL, Rodrigues L, Santos MV, Araújo IB, Moura LS, Lima SS, et al. The burden of Leishmania chagasi infection during an urban outbreak of visceral leishmaniasis in Brazil. Acta Trop 2002; 83:13-8.

12. Contandriopoulos A-P, Champagne F, Denis J-L, Peneault R. A avaliação na área da saúde: conceitos e métodos. In: Hartz ZMA, organizadora. Avaliação em saúde: dos modelos conceituais à prática na análise da implantação de programas. Rio de Janeiro. Editora Fiocruz; 2000. p. 29-47.

13. Ferreira CSV, Silva LMV. Intersetorialidade em saúde: um estudo de caso. In: Hartz ZMA, Silva LMV, organizadoras. Avaliação em saúde: dos modelos conceituais à prática na avaliação de programas. Rio de Janeiro: Editora Fiocruz; 2005. p. 103-50.

14. Luz ZMP, Schall V, Rabello A. Evaluation of a pamphlet on visceral leishmaniasis as a tool for providing disease information to healthcare professionals and laypersons. Cad Saúde Pública 2005; 21:608-21.

15. Gyorkos TW. Monitoring and evaluation of large scale helminth control programmes. Acta Trop 2003; 86:275-82.

16. Rutstein DD, Berenberg W, Chalmers TC, Child CG, Fishman AP, Perrin EB. Measuring the quality of medical care: a clinical method. N Engl J Med 1976; 294:582-8.

Submitted on 20/Sep/2007

Final version resubmitted on 24/Apr/2008

Approved on 12/Aug/2008 